\title{
Understanding University Students' Use of Facebook for Collaborative Learning
}

\author{
Fariza Khalid
}

\begin{abstract}
This paper presents the findings of a study which focused on the integration of Facebook and other Web 2.0 technologies in enhancing the learning process among undergraduate students through online collaborative sharing activities. Respondents were 22 students from two tutorial groups who enrolled in the Educational Technology course in the Faculty of Education, Universiti Kebangsaan Malaysia. Data generation was done through online interviews and documentation of the students' online collaborative sharing and learning activities. The results of thematic analysis indicate that the students found the online sharing activities fun to get involved in and useful for gaining instant support and replies, and their communal interaction and collaboration were also enhanced.
\end{abstract}

Index Terms-Facebook, group, learning, online, web 2.0.

\section{INTRODUCTION}

Facebook is a social network application that connects users from different parts of the world. It becomes the most widely used social networking application in the world with more than one million users worldwide [1]. Facebook offers not only space sharing materials such as videos, audio and photos, but also allows users to have synchronous as well as asynchronous communication [2]. The availability of uploading and downloading materials thus, have supported the use of Facebook in learning process [3]. Through the usage of Facebook, it was proven that students could enhance their communication and collaborative learning skills [3], [4].

Another feature of Facebook that enables more collaborative sharing activities is its ability to help users to create groups which are aimed at a particular group of people [5]. Previous research has revealed that students are comfortable with using Facebook in teaching and learning in their faculty; see for example [6] and [7], who states that 39\% of college students in his survey showed their need to regularly engage in online discussions with their faculty through Facebook. In the Malaysian context, a study by [8] has revealed that the usage of Facebook among university students in Malaysia for social purposes is high $(\min =3.82)$; however, the usage of this platform for educational purposes is still moderate $(\mathrm{min}=3.60)$. From the overall findings of their study, Zaidatun et al. conclude that most students surveyed agree with the potential of online social networks (e.g. Facebook) to enhance their learning processes. [9] study among students at the Open University Malaysia has found that Facebook is able to captivate the attention and

Manuscript received June, 24, 2016; revised August 28, 2016.

F. Khalid is with the Universiti Kebangsaan Malaysia, Bangi, 43600 Selangor, Malaysia (e-mail: fariza.khalid@ukm.edu.my). participation of learners, and has the potential to be used for online academic discussions, either as an alternative to learning management systems commonly used in distance education or to complement such platforms.

Students who engaged themselves in online collaborative sharing activities showed better academic performance than those who learned only through traditional lectures [10] Facebook also can increase the level of interaction among students and between students and teachers. Using Facebook, educators can connect with their students, give them assignments and let the students collaborate with each other to complete the tasks given. Collaboration among students is more alive when they use online environments to gain ideas, or to seek help from other group members.

Although there is a growing number of research projects examining the use of social networking sites such as Facebook in teaching and learning ([6], [11]-[14]), very few studies have addressed the development of specific instructions on how to use Facebook and a discussion of "best practice" policies that can be ethically implemented within the classroom. This paper focuses on two main areas: it offers an explicit explanation on how the integration of Web 2.0 could be implemented by others to create supportive learning communities for students, and discusses the effectiveness of the integration of Facebook (and other Web 2.0 applications) in enhancing collaborative sharing activities from the students' perspective.

\section{PuRPoSe OF THE STUdy}

The study was conducted to examine two things; firstly, the effectiveness of Facebook in supporting students' learning and secondly, to determine the applications available in Facebook that supported learning.

\section{METHOD}

\section{A. Instrument}

Data was collected using online structured interviews. In the final tutorial session, the students were asked to write their thoughts and reflections on questions that were sent to them via Dropbox. They were then asked to upload a file with complete answers to the same Dropbox folder. This method was used to collect data from the students as it would save time and also eliminate the need for face-to-face interviews; it allowed the researcher to interview more than one participant at the same time, because a standard interview schedule or list of questions could be sent individually to several participants at once. In addition, online research participants may be more 
relaxed because they are communicating with the researcher from the comfort of a familiar environment. As a result, they may be willing to discuss sensitive or personal matters, such as emotions or disorders that are hard to reveal in person [15], [16].

The questions posted in Dropbox aimed to examine broader aspects of Web 2.0 including the use of metacognitive reflection through personal blogs, the process of forming a community of practice and the effectiveness of Facebook in general (in terms of the integration of other Web 2.0 applications). However, for this paper, I will only focus on the last issue, i.e. the effectiveness of Facebook as an online platform for collaborative sharing activities for students. Two related questions were:

1) How do you value the overall use of Facebook as a platform for your collaborative sharing activities among your classmates?

2) Name the application(s) utilised in our Facebook group that you think are beneficial for your learning process, and please explain why.

\section{B. Participants}

The research participants were 22 second-year undergraduate students from a group of 87 students who were enrolled in the Educational Technology course. These 22 students were from two tutorial groups under the supervision of the researcher. All the students were invited to a group created using Facebook at the very first tutorial. As all of them already had their own Facebook account, it was easy to get them to participate. Although they came from two tutorial groups, only one Facebook group was created for their use. All these students knew each other before they 'met' in this virtual group, as they were from the same faculty and had attended the same courses in the previous semesters.

\section{The Process}

In this section, I will explain how Web 2.0 applications were integrated into the Facebook group to support the students' learning. Apart from Facebook as the main platform other Web 2.0 applications, including Wallwisher, SurveyMonkey, Skydrive, Dropbox and a few others were used. At the beginning of the Educational Technology course tutorial class, an online group was created using Facebook as a collaborative sharing platform for the students. Students were invited to join the Educational Technology course group which was set as a closed group (Fig. 1). This was to provide space for more private discussions and to prevent unrelated others from reading the discussions.

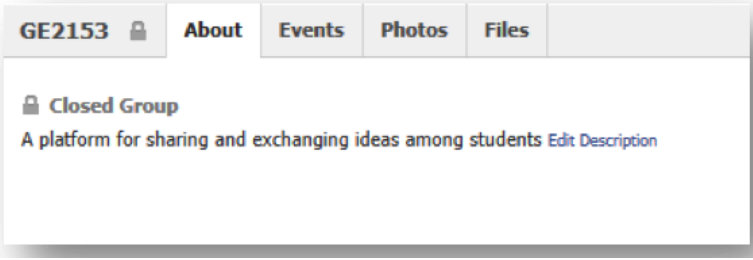

Fig. 1. A description of the educational technology course group.

During the first tutorial, the students were asked to fill in a short survey created using SurveyMonkey (Fig. 2). The objective was to examine their prior knowledge and experiences of using online applications and the purpose of their use. At the end of every tutorial, students were asked to write their reflections on the lessons or activities they had undertaken during the class. For this purpose, I used Wallwisher (Fig. 3) and sometimes I created a new post on the Facebook group's wall, asking the group members to share their thoughts.

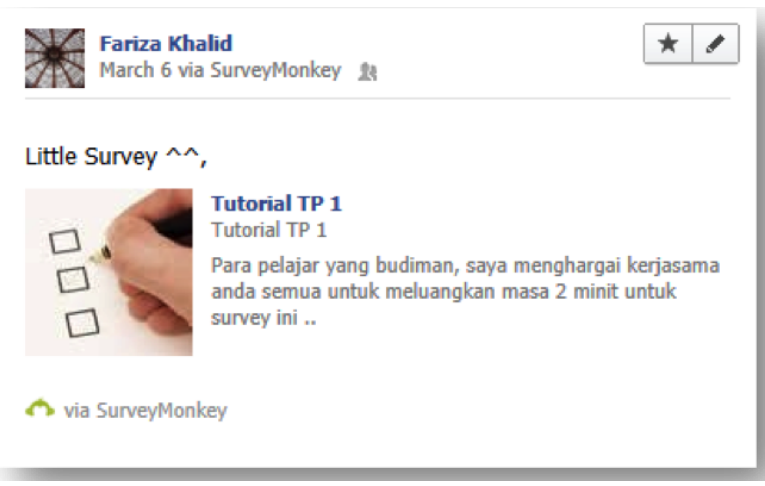

Fig. 2. Short survey on students' current use of online applications using SurveyMonkey.

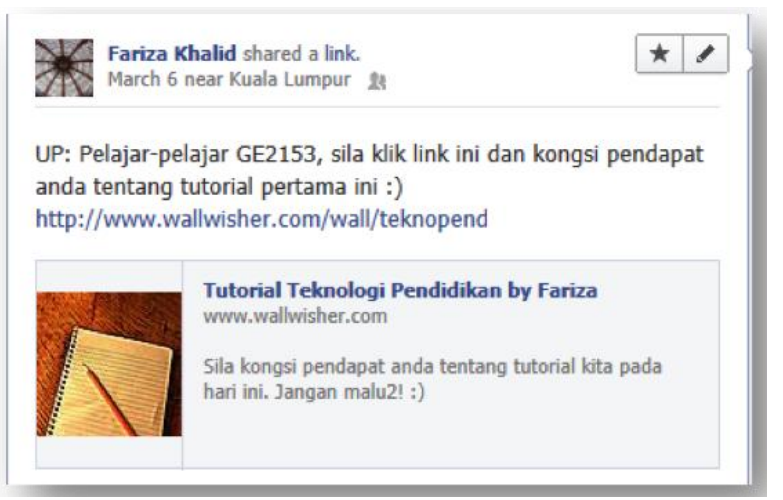

Fig. 3. Obtaining students' reflections on the activities using Wallwisher.

For the purpose of enhancing students' learning and to spur their discussions, other Web 2.0 applications were integrated with the use of Facebook as their online collaborative sharing platform. Among the most widely-used features of Facebook for this group were announcements and information-sharing, as well as links and file-sharing in various forms including tutorial notes, related reading material (Word, PDF and PowerPoint), videos (e.g. YouTube), links and photos.

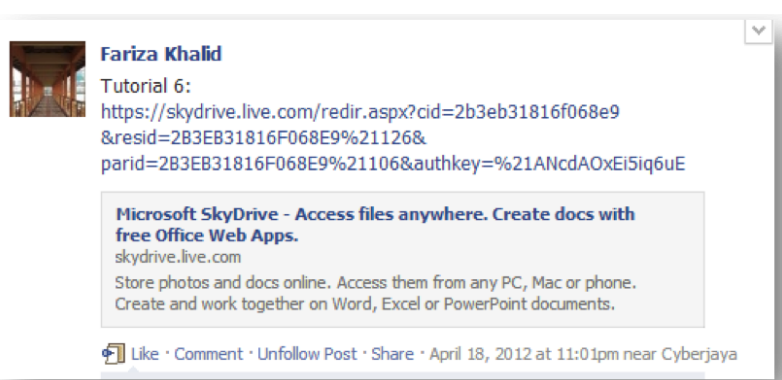

Fig. 4. Sharing tutorial notes with students via Skydrive.

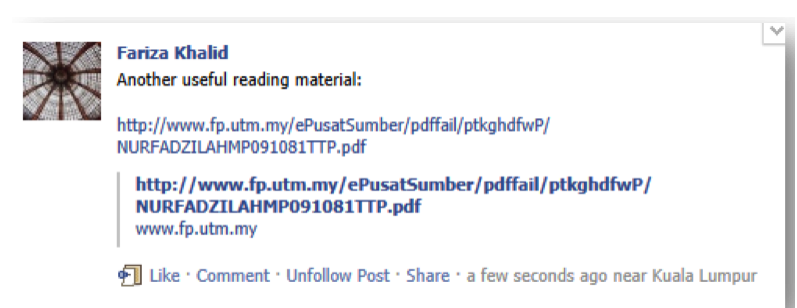

Fig. 5. Sharing links to related reading materials. 
Sometimes there was a need to gather students' opinions on certain activities. For this purpose a poll feature in Facebook was utilised (Fig. 6).

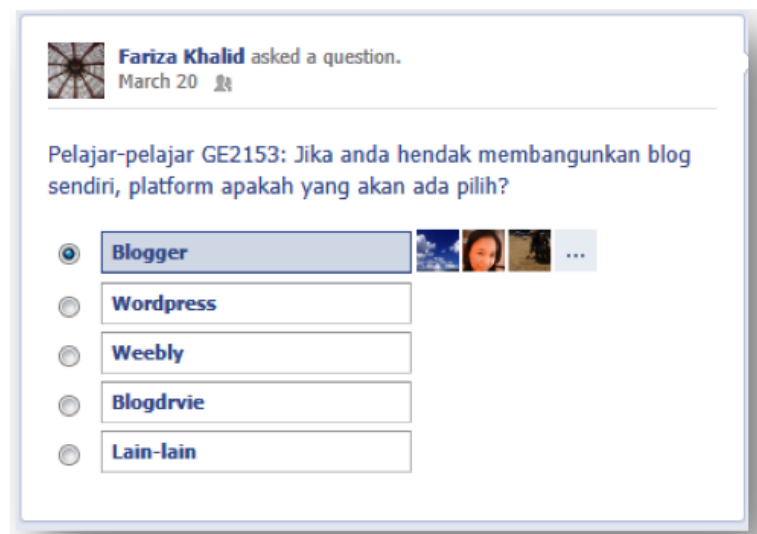

Fig. 6. Gaining students' consensus using a poll in Facebook.

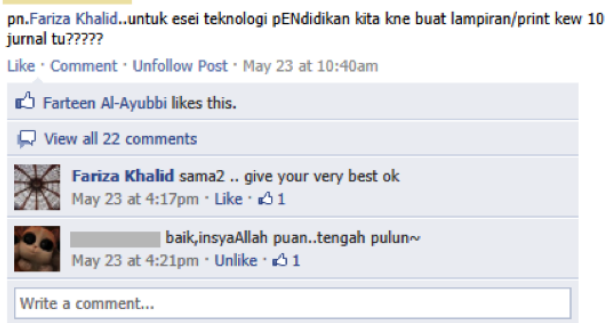

Fig. 7. Student asking for further explanation on the assignment.

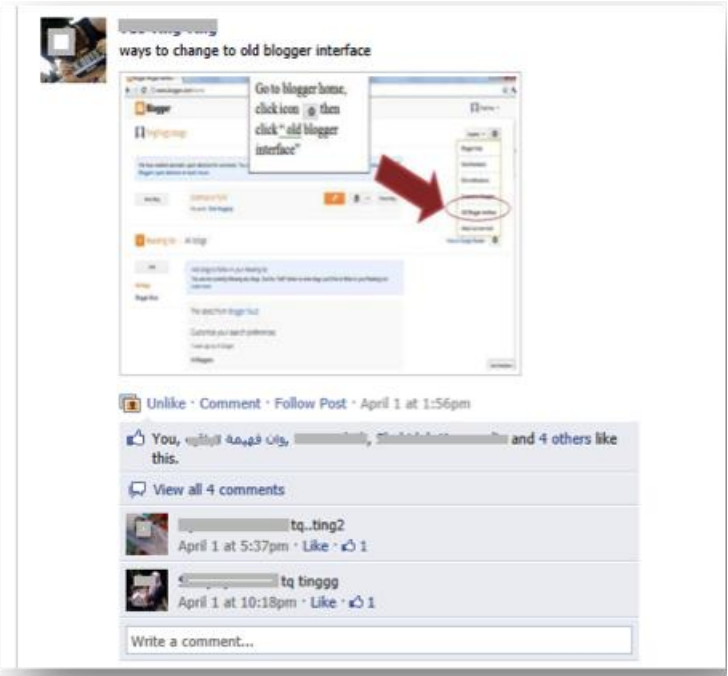

Fig. 8. Student sharing information with others.

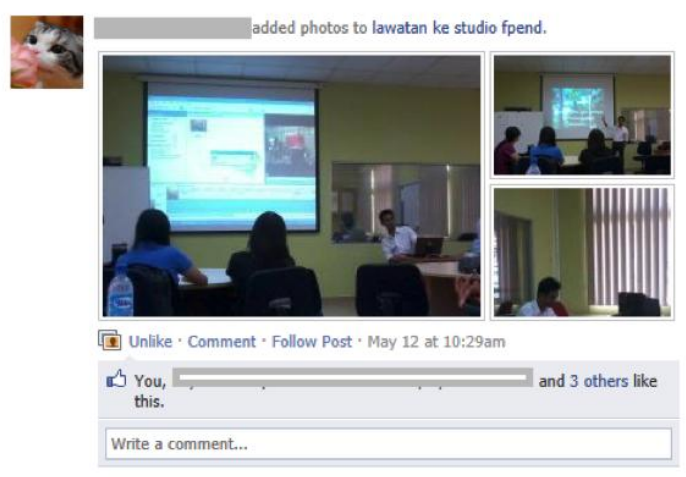

Fig. 9. Student sharing photos with others.
This group was actively used by the students for several purposes, such as to get clarifications or explanations on topics they were unsure about, and to share information with their classmates as shown in Fig. 7, 8 and 9.

\section{RESULT}

\section{A. The Effectiveness of Facebook in Supporting Learning}

Facebook is viewed as effective by the students as it offers many activities for learning. For instance, using Facebook, lecturers shared lecture and tutorial notes that later are used by students for reference and in preparation for the examination. Students seemed to appreciate lecturer's effort to share all learning materials related to the topics discussed every week as can be seen in one of the students answer:

I think what has been done in our Facebook group is great. Dr. F used it to upload all the notes from the first tutorial until the last one. This helped us to do revision as preparation before the final exam. She also provided us with a list of all the assignments which I regularly referred to. (Salma)

Students also mentioned the benefit of the videos shared in the group. They found that watching videos helped them to complete the video assignment. In Educational Technology course, they were required to work in groups and create an educational video as one of their assignments.

The Facebook group is very beneficial for me. Through Facebook, I get additional information about the topics, for example, how to edit videos and take pictures using the correct techniques by watching the YouTube video shared in the group. I also have access to the lecture and tutorial notes. (Aini)

Apart from that, students also viewed the Facebook group as a useful platform as there was active sharing of information going on in the group. Not only was there information provided by the lecturer, but there was also information shared by the students. Information such as announcements, updates on the assignments and the venue for photography site meetings were shared, in addition to various materials related to Educational Technology topics. What made the Facebook group an appreciated platform was the fact that it compiled all the materials on one 'page':

It is easy to have everything in one place. Once I open up this Facebook group, I can access all linked or uploaded materials. Sometimes when you save something on your computer you tend to forget where the folder is. But here [in the EDU2153 group] I can see everything. (Mursyid)

These notes can also be stored and easily searched if required. So I do not have to worry. In addition, we are free to ask questions related to the problems we face in our Facebook group. (Aisya)

Being part of the Facebook group members, students have an access to updated information. This is because, they admitted that they are regularly checked their Facebook updates. After all, the notifications were send to their Facebook alerts which could be easily accessed using their smartphones. One of the examples:

Another thing is that we don't miss the information. All the announcements, notes or discussions can be viewed by all members via our smartphone. We do not have to ling in to our 
emails to see notifications. (Zaini)

At the same time, silent readers could follow the discussions and benefit from the activity without having to take part actively:

Even though I was not involved in the discussions, I learned from what had been said or explained by the lecturer. It is a practical way of giving 'justice' to all students. Sometimes I was not involved, but I did read what others wrote. (Kamariah)

The availability of Internet access almost everywhere in the faculty and on campus enabled the students to get online anytime they wanted to. The analysis indicates that 18 students mentioned that access to Facebook anywhere and anytime gave them freedom in their learning. For example:

Facebook can be used as a site for sharing information between students and lecturers. In addition, it can save time so that everybody can interact anywhere or anytime they want to. It is good that we are not bounded by a specific period of time to participate in discussions. (Aida)

Lecturers can easily upload records to groups to share with the students, and the students can ask questions they do not understand about the lectures.

We were able to ask any questions to the lecturer and she replied so fast. It was a surprise also to see her comments even late at night, when we were still doing our assignments! (Zaini)

Students found that the Facebook group enabled them to gain support or help from others. As assignments in the Educational Technology course involved lots of hands-on activities such as photography, video-making or development of other 3D materials, students needed more support so as to be able to complete their tasks. This can be seen from their answers:

I used the group to ask others about how to do our assignments. I think we had very active interaction there. For example, in creating a video task, we [the group team] discussed our project together using the inbox. It is very convenient that we can directly share links, files or even the photos to express our ideas. (Muhayah)

Students were also seen to post their questions on the group wall. Again, the interaction surrounding the topic had benefit for others who were not involved in the discussions.

One of the benefits of this Facebook group is that I could ask my lecturer questions related to the assignments and she would respond to it. Then, other students might ask additional questions. This helped everybody to understand better. (Zalina)

Another advantage of the Facebook group stated by 16 students was the fact that they were able to get instant or quick reply from others. This was appreciated by the students as they did not have to wait long before getting support and so they could complete their tasks or assignments more quickly. For example:

I am very satisfied with the discussions among us in the group. I get replies very quickly, as if we are talking to each other face to face, whereas in reality we are in different hostels. That is why every time I wanted to do my assignments I would open up my Facebook account first. (Zalina)

Facebook is known as a social networking site as it promotes social interactions among users. In this study, it was also found that the Facebook group enhanced the relationships between the students, as well as with the lecturer. Even though only nine students mentioned this, it was a vital finding that confirms the importance of good relationships in enhancing interactions in any online learning community [17]. This is also in line with [18], who posit that Facebook has been found to reinforce current relationships among its users. One student stated:

Our Educational Technology course group was effective, not only in helping us getting additional information needed to develop sound understandings of certain theirs or concepts that we learned, but also in strengthening our relationships; student to student as well as student to lecturer. When we had conversations with our lecturer, I felt like I was talking to my own 'sister'. (Muna)

The overall findings are summarised in Table I

TABLE I: THEMES RELATED TO THE USEFULNESS OF FACEBOOK

\begin{tabular}{lcc}
\hline Theme & $\begin{array}{c}\text { Number of } \\
\text { students }\end{array}$ & Percentage \\
\hline $\begin{array}{l}\text { Sharing materials related to the } \\
\text { course }\end{array}$ & 21 & $95.5 \%$ \\
\hline Sharing useful information & 19 & $86.4 \%$ \\
\hline $\begin{array}{l}\text { Ease of access to Facebook } \\
\text { Gaining support or help from } \\
\text { friends and the lecturer }\end{array}$ & 18 & $81.8 \%$ \\
\hline $\begin{array}{l}\text { Instant replies from members of } \\
\text { the group }\end{array}$ & 16 & $77.3 \%$ \\
\hline $\begin{array}{l}\text { Opportunities to have one-to-one } \\
\text { discussions with the lecturer }\end{array}$ & 11 & $50.0 \%$ \\
$\begin{array}{l}\text { Developing good relationships } \\
\text { with friends and the lecturer }\end{array}$ & 9 & $40.9 \%$ \\
\hline \hline
\end{tabular}

\section{B. Applications That Benefitted the Students}

Students were asked to name the application(s) that had been utilised in the Facebook group that thought had been beneficial to their learning process and to explain why. The result of the analysis showed that there were four main applications available in the Computer in Education group that were most beneficial for the students' learning; file-sharing, link-sharing, post and comment space and messaging. In the Computer in Education group, file-sharing included Word, PDF, PowerPoint, photos and videos as the most cited applications. Students stated that the sharing of these files was one of the most beneficial applications for their learning while other students named post and comment space in their Facebook group. For example:

The links are helpful because sometimes I do not know where to look for information. By referring to the links given, I was able to trace other related links as well. I found this to help me a lot. I discovered many other informative sites too. (Farhana)

The availability of the posting and comment space on Facebook was cited by 15 students who found it beneficial. 
I like to write comments. It is just simply straightforward. You just type in your thoughts and press the ENTER button. You can easily remove or delete the comment if you want to. The comments can be read by everyone, which is great. No repetition needed. You can print it out if you want. (Azira)

Another application named as beneficial was messaging, which was mentioned by 11 students. Messaging allows users to have private communication with specific friends or a group of friends.

I love the chatting application which my friends and I used a lot too. We talked and discussed our assignments via the chatting space. It was fun too. Besides discussing in the group, the Facebook messaging application also allows me to send reports and assignments to a friend. This application is easier because I do not need to open Yahoo! Mail to send reports to friends. (Muna)

Five students also mentioned that they were more comfortable engaging in discussions with the lecturer in private messages, as some of them felt lacking in confidence to ask questions in public. This is in line with [18], who posit that specifically, has been found to be used to reinforce current offline relationships.

Most of these students posed questions to the lecturer relating to their assignments, as well as other questions relating to the Computer in Education topics, such as the selection of cameras to be bought, or opinions on which movie making software package should be used.

The inbox allows me to ask questions to my lecturer in private. Sometimes, there are things that we do not have to ask in public. For example, I asked my lecturer about what camera brand she considered to be good and practical to have. I wanted to buy a DSLR [Digital Single Lens Reflex] but I did not have a clue what to look for when purchasing a DSLR. She gave me options, together with photos, which is cool. (Mursyid)

The overall findings are illustrated in Table II.

TABLE II: APPLICATIONS THAT WERE BENEFICIAL

\begin{tabular}{lcc}
\hline \hline Theme & $\begin{array}{l}\text { Number of } \\
\text { students }\end{array}$ & Percentage \\
\hline $\begin{array}{l}\text { File-sharing (Word, PDF, } \\
\text { PowerPoint, photos, videos etc.) }\end{array}$ & 20 & $90.9 \%$ \\
\hline $\begin{array}{l}\text { Link-sharing (websites, Skydrive, } \\
\text { Dropbox, Youtube etc.) }\end{array}$ & 18 & $81.8 \%$ \\
\hline $\begin{array}{l}\text { Post and comment space } \\
\text { Messaging (live chat, inbox) }\end{array}$ & 11 & $68.2 \%$ \\
\hline \hline
\end{tabular}

\section{CONCLUSIONS}

From the findings of this study, it can be concluded that Facebook with the integration of other Web 2.0 applications has the potential to be used for online collaborative sharing activities and to spur active learning for students, either as a core platform for learning, or as an alternative platform. The Facebook group in this study enabled its users to share relevant materials and information, and to gain support and instant replies. Through this, sound relationships among the students and between the students and the lecturer were able to develop. Four main applications (file-sharing, links, post and comment space and messaging) were found to be the most beneficial applications in this group. All these applications could be used at the optimum level as these could engage learners in sustained conversations with others in the online group [19]. It is also important to note here that, in addition to students' participation, lecturers or teachers should play their roles too. The lecturer's engagement in an online learning group would help their students feel their presence and therefore could better motivate their involvement.

\section{REFERENCES}

[1] J. Constine. Pinterest Hits 10 Million U.S. Monthly Uniques Faster Than Any Standalone Site Ever. [Online]. (2012). Available: http://techcrunch.com /2012/02/07/pinterest-monthly-uniques/

[2] F. Khalid, M. Y. Daud, and A. A. Karim, "The selection of technology applications as information sharing medium among post graduate university students," in Proc. the ASEAN Comparative Education Research Network Conference, pp. 2011-2027, 2015

[3] D. Bateman and J. Willems, "Facing off: Facebook and higher education" in Misbehaviour Online in Higher Education, A. Wankel and C. Wankel, Eds. Bingley, UK: Emerald, pp. 53-180, 2012.

[4] M. K. Kabilan, N. Ahmad, and M. J. Z. Abidin, "Facebook: An online environment for learning of English in institutions of higher education?" Internet and Higher Education, vol. 13, pp. 179-187, 2011.

[5] N. Sewlyn, "Applications as alternative environments for informal learning - A critical review," presented at OCEDKERIS International Expert Meeting on ICT and Educational Performance, Cheju Island, South Korea: Organization for Economic Co-Operation and Development, 2007.

[6] A. Hewitt and A. Forte, "Crossing boundaries: Identity management and student/faculty relationships on the Facebook," presented at Computer Supported Cooperative Work Conference, Banff, Alberta, Canada, 2006.

[7] J. Fischman, "Dear professor, students want to chat with you," The Chronicle of Higher Education, 2008

[8] Z. Tasir, S. Jacquelin, and H. J. Harun, "Penggunaan Alat Rangkaian Sosial di kalangan Pelajar di sebuah IPTS di Kota Kinabalu, Malaysia," Jurnal Teknologi Pendidikan Malaysia, vol. 1, no. 1, pp 31-47, 2012

[9] T. Lim, "The use of Facebook for online discussions among distance learners," Turkish Online Journal of Distance Education, vol. 11, no. 2, pp. 72-81, 2010.

[10] F. Khalid, "Students' views on the use of e-portfolio and support given to promote their computer Learning for educational purposes," Recent Advance in Telecommunications, Informatics and Educational Technologies, pp. 54-59, 2014

[11] L. Charnigo and P. Barnett-Ellis, "Checking out Facebook.com: The impact of a digital trend on academic libraries," Information Technology and Libraries, vol. 26, pp. 23-34, 2007.

[12] M. Kent, "Changing the conversation: Facebook as a venue for online class discussion in higher education," MERLOT Journal of Online Learning and Teaching, vol. 9, 4, pp. 546-565, 2013.

[13] M. Mintz, "Facebook friend issues between doctor and patient, medpageToday's KevinMD.com: Social media's leading physician voice, 2010.

[14] P. Ractham and D. Firpo, "Using social networking technology to enhance learning in higher education: A case study using Facebook," presented at the 44th Hawaii International Conference on System Sciences, 2011.

[15] N. Hunt and S. McHale, "A practical guide to the e-mail interview," Qualitative Health Research, pp. 1415-1421, 2007.

[16] C. Mann and F. Stewart, "Internet interviewing," Postmodern Interviewing, pp. 603-627, 2003.

[17] E. Wenger, Communities of Practice: Learning, Meaning, and Identity, NY: Cambridge University Press, 1998.

[18] N. B. Ellison, C. Steinfield, and C. Lampe, "The benefits of Facebook "Friends:', Social capital and college students' use of online social network sites," Journal of Computer-Mediated Communication, vol. 12, no. 4, pp. 1143-1168, 2007. 
[19] F. Khalid et al., "Reflective thinking: An analysis of students' reflections in their learning about computers in education," Creative Education, vol. 6, pp. 2160-2168, 2015.

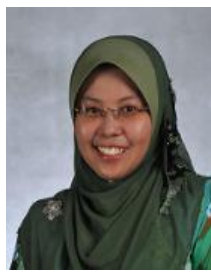

F. Khalid was born in Terengganu, Malaysia and received her $\mathrm{PhD}$ from the University of Nottingham in instructional technology. She is currently a senior lecturer at the Faculty of Education, Universiti Kebangsaan Malaysia (UKM). She is also an e-learning coordinator of the Faculty of Education, UKM. Her research interests include online communities of practice, learner's and professional identities and ubiquitous learning. She has published numerous peer reviewed journa articles and she has written book chapters on educational technology and communities of practice. 